Tinjauan Pustaka

\title{
Diagnosis dan Tatalaksana Klaudikasio Intermiten
}

\author{
Nani, Masrul Syafri
}

\begin{abstract}
Abstrak
Klaudikasio intermiten adalah ketidaknyamanan otot ekstremitas bawah yang dirasakan saat latihan dan hilang dengan istirahat dalam 10 menit. Pasien akan merasakan kelelahan otot, sakit atau kram pada saat aktivitas. Klaudikasio intermiten merupakan gejala yang paling sering muncul pada penyakit arteri perifer. Proses atherosklerosis merupakan penyebab dasar munculnya klaudikasio intermiten. Diagnosis klaudikasio intermiten ditegakkan berdasarkan anamnesis dan pemeriksaan $\mathrm{ABI}$, dan pemeriksaan penunjang lainnya seperti DUS, CTA, MRA, dan DSA. Penatalaksanaan klaudikasio intermiten terdiri dari optimalisasi kontrol faktor resiko dan gejala. Pilihan terapi untuk meredakan gejala terdiri dari terapi non invasif (dengan latihan dan obat-obatan) dan terapi invasif (revaskularisasi). Sampai saat ini masih terdapat perdebatan efektifitas antara terapi invasif dan terapi non invasif.
\end{abstract}

Kata kunci: klaudikasio intermiten, atherosklerosis

\begin{abstract}
Intermittent claudication is a discomfort in the lower extremities that is felt during exercise and is lost with rest in 10 minutes. The patient will feel muscle fatigue, pain or cramps during activity. Intermittent claudication is the most common symptom in peripheral artery disease. Atherosclerosis process is a basic cause of intermittent claudication. The diagnosis of intermittent claudication is based on history and $A B I$ examination, and other investigations such as DUS, CTA, MRA, and DSA. Management of intermittent claudication consists of optimizing the control of risk factors and symptoms. Treatment options for relieving symptoms consist of non-invasive therapy (with exercise and medication) and invasive therapy (revascularization). Until now there is still a debate about the effectiveness between invasive therapy and non-invasive therapy
\end{abstract}

Keywords: intermittent claudication, atherosclerosis

Affiliasi penulis : Bagian Kardiologi dan Kedokteran Vaskular Fakultas Kedokteran UNAND / RSUP Dr. M. Djamil.

Korespondensi : Jalan Perintis Kemerdekaan Padang

kardiologiunand@yahoo.com Telp: 075136494

\section{Pendahuluan}

Klaudikasio berasal dari bahasa latin

"claudicare" yang berarti lemas. Klaudikasio sendiri didefinisikan sebagai ketidaknyamanan otot ekstremitas bawah yang dirasakan saat latihan dan hilang dengan istirahat dalam 10 menit. Pasien akan merasakan kelelahan otot, sakit atau kram pada saat aktivitas. Gejala paling sering dirasakan di betis, tetapi juga dapat dirasakan di paha atau pantat. ${ }^{1}$

Klaudikasio intermiten merupakan gejala yang paling sering muncul pada penyakit arteri perifer (PAP) dan diperkirakan 20 - 40 juta orang di dunia mengalami gejala klasik tersebut. Penyakit arteri perifer sendiri merupakan masalah kesehatan global yang dialami lebih dari 200 juta individu. Prevalensi PAP juga meningkat dalam dekade terakhir ini, bahkan meningkat mendekati $25 \%$ antara tahun 2000 dan 2010. ${ }^{2}$ Pada penelitian Hirsch dkk tahun 2005, ditemukan jumlah penderita PAP di layanan primer akan meningkat $10 \%$ pada populasi yang lebih tua.
Bahkan penelitian di Swedia tahun 2007 melaporkan hampir seperlima populasi manula (60-90 tahun) menunjukkan gejala PAP dengan 6,8\% menderita klaudikasio intermiten. ${ }^{3}$

Klaudikasio intermiten bukanlah PAP yang mengancam nyawa ataupun mengancam ekstremitas. Namun, mempunyai dampak negatif pada kualitas hidup dan dihubungkan dengan peningkatan resiko penyakit kardiovaskular. ${ }^{4}$ Peningkatan kualitas hidup merupakan tujuan utama terapi klaudikasio intermiten. ${ }^{1}$

Penatalaksanaan klaudikasio intermiten terdiri dari optimalisasi kontrol faktor resiko dan gejala. Pilihan terapi untuk meredakan gejala terdiri dari terapi non invasif (dengan latihan dan obat-obatan) dan terapi invasif (revaskularisasi). ${ }^{5}$ Sampai saat ini pilihan terapi non invasif ataupun invasif masih dalam perdebatan. Oleh sebab itu tinjauan pustaka ini bertujuan untuk membahas penatalaksanaan terkini klaudikasio intermiten. 


\section{Pembahasan}

\section{Faktor Resiko Klaudikasio intermiten}

Klaudikasio intermiten (KI) merupakan manifestasi dari proses atherosklerosis. Sehingga mempunyai faktor resiko yang sama dengan proses atherosklerosis tersebut. Faktor resiko tersebut diantaranya adalah hipertensi, diabetes mellitus, merokok dan faktor keturunan. Faktor keturunan dan merokok tampaknya menjadi faktor risiko yang paling penting untuk pengembangan dan perkembangan klaudikasio intermiten. ${ }^{4}$ Selain itu, berdasarkan penelitian Kollerits dkk tahun 2008 terdapat hubungan antara paparan merokok dan klaudikasio intermiten. ${ }^{6}$ Diabetes juga sangat terkait dengan perkembangan gejala klaudikasio intermiten dan selain itu memperburuk prognosis akhir penyakit ini. ${ }^{7}$ Hipertensi dan kolesterol serum juga faktor yang berkontribusi dalam klaudikasio intermiten. ${ }^{8}$ Faktor-faktor ini akan menurunkan kualitas hidup dan kompensasi sirkulasi perifer. Sehingga tidak mengherankan jika sebagian besar pasien klaudikasio intermiten juga memiliki lesi atherosklerotik vaskular lainnya. ${ }^{9}$

\section{Gambaran Klinis Klaudikasio Intermiten}

Gejala utama pada KI adalah nyeri pada anggota badan yang terkena yang diprovokasi oleh latihan. Individu dengan $\mathrm{KI}$ menunjukkan aliran darah istirahat yang normal dan bebas dari gejala saat istirahat. Selama latihan, pasokan arteri yang berkurang yang disebabkan oleh lesi vaskular stenosis atau oklusi, menghambat peningkatan fisiologis yang diperlukan dalam perfusi arteri, dan akhirnya menyebabkan nyeri otot. Rasa sakit, paling sering terdapat di betis tapi kadang-kadang mempengaruhi paha atau pantat, menghilang dengan cepat (dalam waktu sepuluh menit) saat istirahat. ${ }^{1}$

Beban kerja yang berat, seperti jalan menanjak atau naik tangga, menyebabkan gejala klaudikasio intermiten muncul lebih cepat. Namun, sebagian besar pasien $\mathrm{KI}$, mengalami gejala yang tidak khas seperti kelelahan otot, kelemahan ataupun mati rasa.

\section{Diagnosis Banding}

Beberapa penyakit bisa menyerupai klaudikasio intermiten dikenal dengan istilah pseudoklaudikasio yang penyebabnya non vaskular.
Tabel 1 menjelaskan perbedaan antara klaudikasio dengan pseudoklaudikasio. ${ }^{4}$

\section{Diagnosis Klaudikasio Intermiten}

\section{- Ankle-Brachial Index (ABI)}

Pemeriksaan primer non invasif pada $\mathrm{KI}$ adalah dengan menggunakan ABI. Berdasarkan ESC guideline 2011, pemeriksaan ABI direkomendasikan I B untuk diagnosis non invasif pada penyakit arteri perifer. Nilai ABI normal adalah 1.4

Pengukuran $\mathrm{ABI}$ dilakukan dengan menggunakan manset sphygmomanometer $10-12 \mathrm{~cm}$ diatas peralatan Doppler. Biasanya tekanan tertinggi di pergelangan kaki dibagi dengan tekanan tertinggi brachial. Namun, pada penelitian lain disebutkan sensitivitas pengukuran $A B I$ jauh lebih baik saat menggunakan tekanan terendah arteri pada kedua pergelangan kaki. ${ }^{10}$

Pada beberapa pasien (diabetes atau penyakit ginjal berat) $A B I$ bukanlah alat diagnostik yang dapat diandalkan. Kalsifikasi berat arteri perifer menjadi non-kompresibel, sehingga meningkatkan nilai $A B I$. Pasien-pasien ini biasanya memiliki $A B I \geq 1,4$, dan diperlukan pengujian non-invasif diperlukan untuk diagnosis PAP. Selain itu, pengukuran $A B I$ mungkin salah jika lesi obstruktif di subklavia atau arteri axillaris. Oleh sebab itu penting mengukur tekanan darah sistemik di kedua lengan, dan menggunakan nilai tertinggi yang diperoleh di lengan untuk perhitungan indeks. Sebagai tes alternatifnya adalah dengan mengukur tekanan sistolik ibu jari kaki dan analisis gelombang Doppler untuk mendeteksi penyakit arteri ekstremitas bawah. Indeks ibu jari kaki dengan brachial $\leq 0,7$ merupakan diagnostik untuk penyakit arteri ekstremitas bawah.$^{10}$

\section{- Treadmill Test}

Pada saat istirahat, pasien dengan $\mathrm{KI}$ mungkin bisa ditemukan nilai $\mathrm{ABI}$ yang normal, sehingga diperlukan stress tes untuk meningkatkan akurasi diagnostik. Dengan mengukur $\mathrm{ABI}$ sebelum dan sesudah treadmill berjalan atau provokasi stres yang sama, setiap lesi vaskular yang signifikan secara hemodinamik dapat diketahui akibat vasodilatasi perifer yang disebabkan oleh latihan. Selain itu treadmill test ini bisa digunakan untuk membedakan antara klaudikasio yang berasal dari vaskuler (tekanan di kaki akan turun setelah latihan) atau neurogenik (tekanan di 
kaki akan tetap sama atau meningkat). Treadmill test juga bisa digunakan untuk menilai efektifitas terapi (rehabilitasi latihan, terapi obat-obatan, atau dengan revaskularisasi). Treadmill dilakukan dengan latihan sampai $3,2 \mathrm{~km}$ dengan tanjakan $10-20 \%$. Terdapat beberapa tehnik seperti peningkatan tanjakan setiap 3 menit dengan tetap berjalan dengan kecepatan yang sama sampai nyeri klaudikasio muncul. Pemeriksaan ini harus tetap didampingi untuk mengamati gejala yang muncul. Namun, pemeriksaan ini tidak dianjurkan pada pasien dengan penyakit jantung koroner berat, gagal jantung, atau dengan gangguan berjalan. ${ }^{4}$ Penurunan tekanan segera setelah uji treadmill, dan terdapatnya gradien antara $15-20 \%$ menegakkan diagnosis PAP. ${ }^{1}$ Pasien yang tidak bisa melakukan treadmill test, bisa dilakukan latihan fleksi pedal. ${ }^{4}$

Tabel 1. Perbedaan Klaudikasio dengan Pseudoklaudikasio ${ }^{4}$

\begin{tabular}{|c|c|c|c|c|c|}
\hline Characteristic & $\begin{array}{l}\text { Intermittent } \\
\text { Claudication }\end{array}$ & Spinal Stenosis & Arthritis & Venous Congestion & $\begin{array}{l}\text { Compartment } \\
\text { Syndrome }\end{array}$ \\
\hline $\begin{array}{l}\text { Character of discom- } \\
\text { fort }\end{array}$ & $\begin{array}{l}\text { Cramping, tightness, } \\
\text { or tiredness }\end{array}$ & $\begin{array}{l}\text { Same symptoms as } \\
\text { with claudication } \\
\text { or tingling, weak- } \\
\text { ness, or clumsi- } \\
\text { ness }\end{array}$ & Aching & $\begin{array}{l}\text { Tightness, bursting } \\
\text { pain }\end{array}$ & $\begin{array}{l}\text { Tightness, bursting } \\
\text { pain }\end{array}$ \\
\hline $\begin{array}{l}\text { Location of discom- } \\
\text { fort }\end{array}$ & $\begin{array}{l}\text { Buttock, hip, thigh, } \\
\text { calf, foot }\end{array}$ & Buttock, hip, thigh & Hip, knee & Groin or thigh & Calf \\
\hline $\begin{array}{l}\text { Exercise-induced dis- } \\
\text { comfort }\end{array}$ & Yes & Variable & Variable & After walking & $\begin{array}{l}\text { After excessive } \\
\text { exercise }\end{array}$ \\
\hline Walking distance & Reproducible & Variable & Variable & Variable & Variable \\
\hline $\begin{array}{l}\text { Discomfort with } \\
\text { standing }\end{array}$ & No & Yes & $\begin{array}{l}\text { Yes, changes with } \\
\text { shift in position }\end{array}$ & $\begin{array}{l}\text { Yes, changes with } \\
\text { shift in position }\end{array}$ & $\begin{array}{l}\text { Yes, changes with } \\
\text { shift in position }\end{array}$ \\
\hline Relief of discomfort & Rapid relief with rest & $\begin{array}{l}\text { Relief with sitting or } \\
\text { otherwise chang- } \\
\text { ing position }\end{array}$ & $\begin{array}{l}\text { Slow relief with avoid- } \\
\text { ance of bearing } \\
\text { weight }\end{array}$ & $\begin{array}{l}\text { Slow relief with leg } \\
\text { elevation }\end{array}$ & $\begin{array}{l}\text { Slow relief with leg } \\
\text { elevation }\end{array}$ \\
\hline Other & $\begin{array}{l}\text { Associated with ath- } \\
\text { erosclerosis and } \\
\text { decreased pulses }\end{array}$ & $\begin{array}{l}\text { History of lower-back } \\
\text { problems }\end{array}$ & $\begin{array}{l}\text { Discomfort at joint } \\
\text { spaces }\end{array}$ & $\begin{array}{l}\text { History of deep ve- } \\
\text { nous thrombosis, } \\
\text { signs of venous } \\
\text { congestion }\end{array}$ & $\begin{array}{l}\text { May occur in ath- } \\
\text { letes after stren- } \\
\text { uous exercise }\end{array}$ \\
\hline
\end{tabular}

\section{- Metode Ultrasound}

Duplex ultrasound/duplex ultrasonography (DUS) menunjukkan anatomi arteri dan aliran darah. Berdasarkan studi meta analisis, sensitivitas DUS untuk mendeteksi angiografi stenosis > 50\% mencapai 85$90 \%$ dengan spesifisitas $>95 \% .^{23}$ Lokasi lesi dapat dilihat dengan ultrasonografi 2 dimensi dan colourDoppler mapping. Sedangkan tingkat stenosisnya dapat diestimasikan dengan analisis gelombang Doppler dan puncak dan ratio systolic velocities. Penggunaan DUS untuk mendeteksi stenosis > 50\% pada ekstremitas bawah sangat baik kecuali untuk arteri pedis. DUS juga berguna untuk mengevaluasi setelah angioplasti atau memonitor graft bypass. ${ }^{11}$

Kelemahan DUS adalah kesulitan menilai lumen pembuluh darah yang mengalami kalsifikasi berat, atau pada pasien dengan ulkus terbuka atau dengan luka parut yang lebar. Kesulitan juga ditemui pada pasien obesitas. Kerugian DUS jika dibandingkan dengan teknik pencitraan lain adalah DUS tidak memberikan pencitraan arteri yang jelas seperti halnya teknik lainnya. Namun, DUS memberikan informasi penting tentang hemodinamik. Pada pasien yang menjalani operasi bypass, DUS berperan dalam menentukan lokasi anastomosis dengan identifikasi dari pembuluh darah yang mengalami kalsifikasi. ${ }^{11}$

\section{- Computed Tomography Angiography (CTA)}

Metode ini memungkinkan untuk imaging dengan resolusi tinggi. Dibandingkan dengan DSA, sensitivitas dan spesifisitas untuk oklusi sudah mencapai tingkat akurasi yang tinggi. Dalam penelitian meta-analisis terbaru, sensitivitas dilaporkan dan spesifisitas dari CTA untuk mendeteksi stenosis aortailiaka $0,50 \%$ adalah $96 \%$ dan $98 \%$. Penelitian yang sama menunjukkan sensitivitas yang sama (97\%) dan spesifisitas (94\%) untuk daerah femoropopliteal, sebanding dengan yang dilaporkan untuk arteri di bawah lutut (sensitivitas 95\%, spesifisitas 91\%). Keuntungan terbesar dari CTA tetap memvisualisasikan kalsifikasi, clip, stent, dan bypass. Namun, beberapa artefak masih dapat muncul. ${ }^{12}$

\section{- Magnetic Resonance Angiography (MRA)}

Teknik ini dapat memvisualisasikan secara non invasif arteri ekstremitas bawah bahkan di bagian 
yang paling distal. Dibandingkan dengan DSA, MRA memiliki sensitivitas yang sangat baik (93-100\%) dan spesifisitas (93-100\%). Keterbatasan penggunaan MRA yaitu pada pasien dengan alat pacu jantung atau implan logam (termasuk stent), atau pada pasien dengan claustrophobia. Agen kontras pada MRA tidak dapat digunakan dalam kasus gagal ginjal yang parah (GFR $30 \mathrm{~mL} /$ menit per 1,73 m2). Selain itu, MRA tidak bisa memvisualisasikan kalsifikasi arteri, sehingga tidak bisa digunakan untuk memilih lokasi anastomosis untuk operasi bypass. ${ }^{13}$

\section{- Digital Subtraction Angiography (DSA)}

Metode ini merupakan standar emas untuk diagnosis PAP, terutama untuk pasien yang menjalani intervensi, terutama bersamaan dengan prosedur endovaskular. Memang, teknik non-invasif memvisualisasikan pencitraan di hampir semua kasus, dengan radiasi yang lebih sedikit, dan menghindari komplikasi punksi arteri < $1 \%$ kasus. Teknik kateterisasi yang sering digunakan adalah transfemoral retrograde. Jika akses femoralis tidak memungkinkan, akses transradial atau pendekatan dan kateterisasi antegrade langsung transbrachial juga bisa dilakukan. ${ }^{4}$ Gambaran hasil CTA, MRA dan DSA ditampikan pada gambar 1.

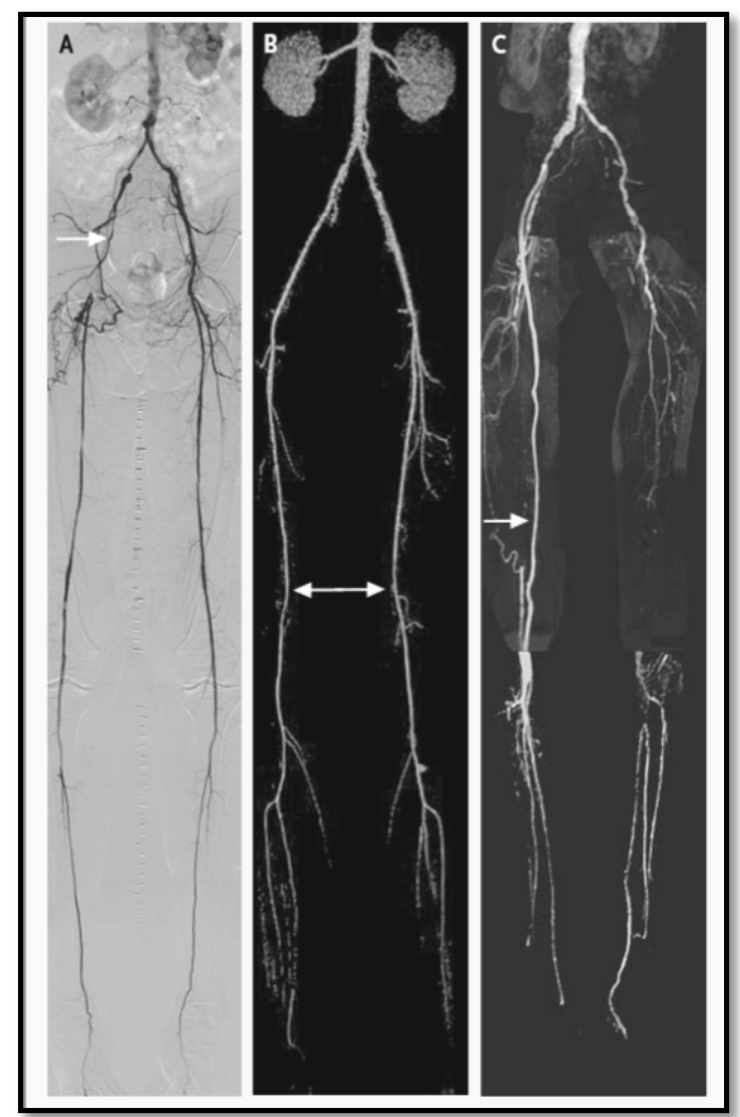

Gambar 1 Aortograms; DSA (A), CTA (B), MRA (C) ${ }^{4}$

\section{Penatalaksanaan Klaudikasio Intermiten}

Pengelolaan klaudikasio intermiten terdiri dari kontrol faktor risiko yang optimal dalam rangka meningkatkan prognosis vital dan meredakan gejala. Pilihan terapi untuk meredakan gejala secara noninvasif dengan latihan disupervisi dan medikamentosa ataupun invasif (revaskularisasi).

\section{- Pengendalian Faktor Resiko}

\section{$>$ Obat Penurun Kolestero}

1. Terapi dengan hydroxymethyl glutaryl coenzyme-A reductase inhibitor (statin) diindikasikan untuk semua pasien dengan penyakit arteri perifer untuk mencapai target $\mathrm{LDL}<100 \mathrm{mg} / \mathrm{dL}$ (IB)

2. Terapi dengan hydroxymethyl glutaryl coenzymeA reductase inhibitor (statin) untuk mencapai target LDL $<70 \mathrm{mg} / \mathrm{dL}$ dengan resiko tinggi kejadian iskemik (Ila $\mathrm{B}$ ).

3. Terapi dengan asam fibroat dapat digunakan pada pasien PAP dengan HDL yang rendah, kadar LDL yang normal dan trigliserida yang tinggi. (Ila C)

$>$ Obat Hipertensi

1. Obat hipertensi diberikan pada pasien hipertensi dengan PAP ekstremitas bawah dengan target tekanan darah $<140 / 90 \mathrm{mmHg}$ (pada pasien tanpa diabetes) atau $<130 / 80$ $\mathrm{mmHg}$ pada pasien dengan diabetes dan gagal ginjal kronik.

2. Beta blocker merupakan obat antihipertensi yang efektif dan bukan kontraindikasi pada pasien PAP (IA)

3. Penggunaan ACE inhibitors pada pasien PAP ekstremitas bawah yang bergejala direkomendasikan sebagai kelas Ila B.

\section{$>$ Terapi Diabetes}

1. Perawatan kaki, termasuk penggunaan alas kaki, pemeriksaan kaki setiap hari, pembersihan kulit dan penggunaan krim pelembab (IB)

2. Terapi diabetes pada pasien dengan PAP ekstremitas bawah dengan obat-obat pengontrol gula dengan target $\mathrm{HbA} 1 \mathrm{C}<7 \%$ efektif untuk menurunkan komplikasi mikrovaskular (Ila C) 


\section{$>$ Berhenti Merokok}

1. Pasien perokok atau bekas perokok sebaiknya ditanyakan mengenai status merokoknya setiap kunjungan.

2. Pasien harus sebaiknya dikonseling dan dikembangkan rencana untuk berhenti merokok baik dengan farmakoterapi dan atau dengan program konseling.

\section{$>$ Antiplatelet dan antitrombotik}

1. Aspirin, dengan dosis 75-325 mg, direkomendasikan sebagai terapi antiplatelet yang aman dan efektif untuk menurunkan resiko infark miokard, stroke, atau kejadian vaskular (IB).

2. Clopidogrel dengan dosis $75 \mathrm{mg}$ per hari direkomendasikan sebagai terapi antiplatelet untuk menurunkan resiko infark miokard, stroke, atau kejadian vaskular (IB).

\section{- Terapi Medikamentosa}

\section{$>$ Cilostazol}

Cilostazol, golongan phosphodiesterase-3 inhibitor. Dalam penelitian Momsen dkk, yang dikumpulkan dari sembilan percobaan (1258 pasien) membandingkan cilostazol dengan plasebo, obat ini dikaitkan dengan peningkatan mutlak $42,1 \mathrm{~m}$ versus plasebo $(P, 0,001)$ selama rata-rata tindak lanjut dari 20 minggu. Dalam meta-analisis lain, berjalan kaki maksimal meningkat rata-rata sebesar $36 \mathrm{~m}$ dengan cilostazol $50 \mathrm{mg} /$ hari, dan hampir dua kali $(70 \mathrm{~m})$ dengan dosis $100 \mathrm{mg}^{14}$ Panduan AHA merekomendasikan cilostazol $100 \mathrm{mg} 2$ kali per hari pada pasien dengan PAP ekstremitas bawah dan klaudikasio intermiten. Efek samping yang paling sering adalah sakit kepala, diare, pusing, dan jantung berdebar. $^{3}$

\section{$>$ Pentoxifilin}

Pentoxifilin dengan dosis $400 \mathrm{mg} 3$ kali per hari merupakan terapi alternative lini kedua setelah cilostazol untuk meningkatkan jarak tempuh pasien klaudikasio intermiten. Obat ini termasuk dalam golongan phosphodiesterase inhibitor yang berfungsi sebagai vasodilator dan antiplatelet. Berdasarkan hasil enam studi meta-analisis terbaru, ditemukan peningkatan signifikan jarak berjalan kaki maksimal dengan pentoxifilin $(59 \mathrm{~m}) .^{15}$

\section{- Obat-obat lainnya}

\section{$>$ Naftidrofuryl}

Naftidrofuryl telah tersedia di Eropa selama bertahun-tahun. Ini adalah golongan 5hydroxytryptamine tipe 2 antagonis yang mengurangi eritrosit dan agregasi trombosit. Efikasi naftidrofuryl diperiksa dalam suatu penelitian meta-analisis dari 5 studi termasuk 888 pasien: bebas rasa sakit berjalan kaki itu secara signifikan meningkat $26 \%$ vs placebo. Hasil yang sama juga dikonfirmasi dengan analisis Cochrane. Efek samping obat ini adalah gangguan pencernaan ringan. ${ }^{15}$

\section{$>$ Carnitine dan Propionil-L-Carnitine}

Obat ini mungkin memiliki efek pada metabolisme otot iskemik. Dalam dua uji coba multisenter, propionil-L-karnitin meningkatkan jarak berjalan kaki dan kualitas hidup yang lebih baik dibandingkan plasebo. Uji coba tambahan diharapkan untuk mengevaluasi keampuhan dalam kelompok besar pasien. ${ }^{16}$

\section{$>$ Buflomedil}

Buflomedil dapat menghambat agregasi platelet dan meningkatkan deformabilitas sel darah merah dan juga memiliki efek adrenolitik. Dalam penelitian yang dilakukkan oleh De Backer dkk, pada 2078 pasien, pasien menunjukkan perbaikan gejala yang signifikan. Namun, dalam meta-analisis ini, hasil ini dikutip sebagai 'moderat' positif, dengan beberapa derajat. Kisaran dosis terapi sempit, dengan risiko kejang. Buflomedil baru-baru ini ditarik dari pasar di beberapa negara Eropa karena efek samping utama dan manfaat yang belum pasti. ${ }^{17}$

Agen farmakologis lainnya seperti inositol, proteoglikan, dan prostaglandin. Meskipun positif, hasil memerlukan lebih lebih lanjut. Sebuah meta-analisis tidak menunjukkan perbaikan yang signifikan dalam jarak berjalan kaki dengan gingko biloba. Kompresi pneumatik intermiten mungkin relevan untuk gejala. Dalam suatu penelitian, ditemukan data dengan kompresi pneumatik intermiten menunjukkan peningkatan aliran darah (13-240\%) di poplitea atau arteri infragenikular. Bahkan jarak berjalan kaki maksimal ditingkatkan sampai dengan $50 \%$ (90 m). ${ }^{18}$ 


\section{- Latihan Olahraga pada Klaudikasio Intermiten}

Berdasarkan ACC/AHA dan ESC, latihan olahraga yang disupervisi merupakan rekomendasi kelas IA sebagai terapi awal klaudikasio. Pada suatu penelitian metaanalisis, latihan dapat meningkatkan waktu tempuh maksimal dengan peningkatan kemampuan berjalan hingga $50-200 \%{ }^{3}$ Selain itu latihan juga dapat meningkatkan jarak tempuh secara signifikan hingga 2 tahun. Pada penelitian metaanalisis lainnya, terapi latihan yang disupervisi menunjukkan perbaikan yang signifikan jarak tempuh maksimal dengan treadmill jika dibandingkan dengan terapi latihan yang tidak disupervisi. ${ }^{19}$

Penelitian terbaru, CLEVER (CLaudication: Exercise Versus Endoluminal Revascularization), yang membandingkan antara farmakoterapi optimal, latihan disupervisi, dan revaskulariasi endovaskuler memperlihatkan superioritas baik program latihan maupun revaskularisasi terhadap farmakoterapi, dengan peningkatan bermakna terhadap kemampuan berjalan pada grup yang menjalani latihan, serta dengan perbaikan kualitas hidup secara umum yang lebih baik pada grup yang menjalani revaskularisasi. ${ }^{20}$

Mekanisme fisiologis latihan terhadap perbaikan gejala klaudikasio belum sepenuhnya dimengerti, namun beberapa penelitian menunjukkan kemungkinan efek yang ditimbulkan sebagai berikut: ${ }^{21}$

1. Meningkatnya efisiensi konsumsi oksigen jaringan otot karena modifikasi pola berjalan sehingga dibutuhkan energi yang lebih sedikit untuk menjalani latihan.

2. Meningkatnya kemampuan metabolisme otot: meningkatnya kapasitas enzim oksidatif berkurangnya kadar acylcarnitine

3. Meningkatnya daya tahan dan kekuatan otot

4. Berkurangnya persepsi nyeri

5. Perbaikan fungsi endotel

6. Peningkatan kolateral

7. Berkurangnya viskositas darah

8. Berkurangnya faktor inflamasi sistemik

9. Memperbaiki faktor kardiovaskuler lainnya: berkurangnya tekanan darah, resistensi insulin, faktor inflamasi (hs-CRP), depresi dan stres psikososial, obesitas, serta perbaikan pada fungsi otonom, reologi darah, dan profil lipid.
Program latihan menggunakan treadmill atau lintasan untuk pasien dengan klaudikasio tercantum pada tabel 2.6. Program latihan terdiri atas 3-5 sesi per minggu selama 12-24 minggu. Latihan dijalankan dibawah pengawasan dengan pengukuran objektif terhadap keluhan klaudikasio, jarak dan lama berjalan maksimal, serta tanda-tanda iskemia miokard. Pengukuran tekanan darah, denyut nadi, dan elektrokardiogram 12 lead dilakukan selama latihan. Target program adalah peningkatan jarak tempuh maksimal dan jarak berjalan tanpa nyeri. Setelah program yang disupervisi selesai, progam latihan dilanjutkan dirumah dengan pola yang sama.

Keterbatasan pada program latihan ini terutama diakibatkan oleh adanya komorbiditas. Penyakit otot, sendi, dan saraf merupakan faktor penghambat untuk latihan. Penyakit jantung ataupun paru kronik menurunkan kapasitas fungsional sehingga pasien tidak dapat mencapai tingkatan latihan yang diharapkan. Kurangnya kesediaan pasien untuk menjalani program latihan menyebabkan hasil yang latihan yang tidak sesuai dengan data dari berbagai penelitian. Umumnya ini timbul karena pasien tidak menganggap program latihan ini sebagai suatu terapi, namun hanya sebagai program tambahan (adjuvant), sehingga tidak menimbulkan minat. Salah satu metode untuk mengatasinya adalah dengan memberikan program latihan rumah yang terukur dan dimonitor dengan baik, yang memberikan hasil serupa dengan program latihan dibawah supervisi. ${ }^{2}$

\section{- Terapi Intervensi}

Pada kasus klaudikasio yang berat terapi dengan medikamentosa atau pun dengan terapi latihan yang disupervisi, seringkali tidak memadai untuk memperbaiki gejala sehingga diperlukan pencitraan lesi untuk mengetahui lokasi yang tepat dan karakteristik lesi. Ini akan membantu apakah terapi intervensi memungkinkan atau tidak. Bukti keuntungan jangka panjang revaskularisasi dibandingkan latihan yang disupervisi dan terapi medikamentosa masih belum dapat disimpulkan, terutama pada pasien dengan klaudikasio yang ringan sampai sedang. ${ }^{4}$

\section{- Terapi Endovaskular}

Pemilihan strategi revaskularisasi yang paling tepat harus ditentukan berdasarkan kasus-per kasus. Hal utama yang harus dipertimbangkan adalah 
kesesuaian anatomi, komorbiditas, ketersediaan dan keahlian lokal, dan preferensi pasien. TransAtlantic Inter-Society Consensus for the Management of Peripheral Arterial Disease (TASC II) mengklasifikasikan lesi berdasarkan lokasi dan karakteristik lesi (tabel 2, tabel 3 dan tabel 3). ${ }^{4}$

Tabel 2 Klasifikasi TASC II Lesi Aorto lliaka ${ }^{4}$

\begin{tabular}{|c|c|}
\hline Tipe A & $\begin{array}{l}\text { - stenosis unilateral atau bilateral CIA } \\
\text { - } \text { stenosis pendek }((\leq 3 \mathrm{~cm}) \text { unilateral } \\
\text { atau bilateral EIA }\end{array}$ \\
\hline Tipe B & $\begin{array}{l}\text { - } \text { stenosis pendek }(\leq 3 \mathrm{~cm}) \text { infrarenal } \\
\text { - } \text { oklusi CIA unilateral } \\
\text { - } \text { stenosis } 3-10 \mathrm{~cm} \text {, tunggal atau } \\
\text { multiple melibatkan EIA tetapi tidak } \\
\text { sampai CFA } \\
\text { - } \\
\text { oklusi EIA unilateral tidak melibatkan } \\
\text { origin iliaka interna atau CFA }\end{array}$ \\
\hline Tipe C & 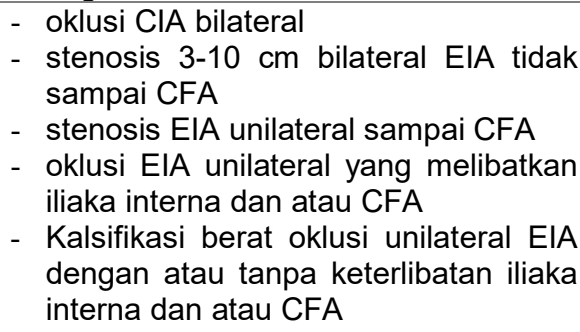 \\
\hline Tipe D & $\begin{array}{l}\text { - oklusi aortailiaka infra renal } \\
\text { - lesi difus melibatkan aorta dan kedua } \\
\text { a.iliaka memerlukan terapi } \\
\text { - Multipel stenosis difus melibatkan CIA, } \\
\text { EIA dan CFA unilateral. } \\
\text { - oklusi unilateral CIA dan EIA } \\
\text { - oklusi bilateral EIA } \\
\text { - stenosis iliaka pada pasien AAA yang } \\
\text { memerlukan terapi dan tidak bisa } \\
\text { dilakukan endograft atau lesi lain yang } \\
\text { memerlukan bedah terbuka iliaka atau } \\
\text { aorta }\end{array}$ \\
\hline
\end{tabular}

CIA : common iliac artery; EIA : external iliac artery; CFA : common femoral artery; AAA : abdominal aortic aneurysm

Indikasi revaskularisasi endovaskular tergantung dari tingkat kesulitan harian yang berhubungan dengan klaudikasio setelah diberikan terapi farmakologis dan latihan yang disupervisi. Pada kasus dengan lesi aortoiliaka, dengan gejala keterbatasan, revaskularisasi sebaiknya dilakukan dari awal tanpa diawali terapi konservatif. Sedangkan untuk pembedahan terbatas untuk lesi yang luas tanpa kemungkinan dilakukan terapi endovaskular. ${ }^{22}$

Tabel 3 Klasifikasi TASC II Lesi Femoropopliteal ${ }^{4}$ Tipe A - stenosis tunggal, panjang $\leq 10 \mathrm{~cm}$ - oklusi tunggal, panjang $\leq 5 \mathrm{~cm}$

Tipe B - multiple lesi, masing-masing $\leq 5 \mathrm{~cm}$ - stenosis tunggal atau oklusi $\leq 15 \mathrm{c}$ tanpa melibatkan a. popliteal infra genikulata
- lesi tunggal atau multiple tanpa pembuluh tibia continuous

- oklusi dengan kalsifikasi berat $\leq 5$ $\mathrm{cm}$

- oklusi popliteal satu sisi

Tipe C - multiple stenosis atau oklusi $>15$ $\mathrm{cm}$ dengan atau tanpa kalsifikasi

- stenosis rekuren atau oklusi yang memerlukan terapi setelah 2 intervensi endovascular

Tipe D - oklusi total kronik CFA atau SFA $(>20 \mathrm{~cm}$, melibatkan a. popliteal)

- oklusi total kronik a.poplitea dan proksimal pembuluh trifurkasio.

CFA : common femoral artery; SFA : superficial femoral artery.

Tabel 4 Klasifikasi TASC Lesi Infrapopliteal ${ }^{27}$

Tipe A - stenosis tunggal, panjang $\leq 5 \mathrm{~cm}$ dengan stenosis atau oklusi a.tibialis sisi yang sama atau a.tibialis yang lebih parah.

Tipe B - multiple lesi, masing-masing $\leq 5 \mathrm{~cm}$, atau total $\leq 10 \mathrm{~cm}$ atau oklusi tunggal $\leq 3 \mathrm{~cm}$ dengan stenosis atau oklusi a.tibialis sisi yang sama atau a.tibialis yang lebih parah.

Tipe C - multiple stenosis atau oklusi $>10 \mathrm{~cm}$ dengan stenosis atau oklusi a.tibialis sisi yang sama atau a.tibialis yang lebih parah.

Tipe D - multiple oklusi dengan target a. tibialis dengan total panjang lesi $>10$ $\mathrm{cm}$ atau kalsifikasi padat atau tanpa kolateral. A. tibialis lainnya juga oklusi atau kalsifikasi padat

Kelemahan utama dari intervensi endovaskular dibandingkan dengan operasi adalah patensi jangka panjang yang lebih rendah. Saat ini tidak ada metode selain stenting untuk meningkatkan setidaknya patensi jangka menengah angioplasti. Penggunaan drug-eluting balloons tampaknya menjanjikan, namun masih sedikit data mengenai hal ini. Secara umum, intervensi endovaskular tidak diindikasikan sebagai terapi profilaksis pada pasien tanpa gejala. ${ }^{4}$

Tujuan utama implantasi stent adalah: (i) untuk meningkatkan hasil primer yang tidak memadai (seperti sisa stenosis, recoil yang luas, diseksi yang mengurangi aliran) dan (ii) untuk meningkatkan patensi jangka panjang. Penempatan stent umumnya harus dihindari di daerah yang lentur seperti sendi pinggul dan lutut. Implantasi stent juga harus dihindari pada segmen yang akan digunakan pada operasi bypass. ${ }^{4}$

Obstruksi pada distal aorta dan arteri iliaka lebih dipilih untuk dilakukan teknik endovaskuler, dan direkomendasikan untuk lesi TASC A-C. Rendahnya 
angka kesakitan dan kematian sekitar 0,90\% menjadikan teknik endovaskuler sebagai pilihan pertama. Berdasarkan suatu penelitian meta analisis, stenting direkomendasikan sebagai terapi primer untuk oklusi dan stenosis arteri iliaka komunis dan eksterna. ${ }^{4}$ Pada lesi femoropopliteal TAS A-C, endovaskular sebagai strategi awal direkomendasikan sebagai kelas IC. Sedangkan endovascular pada lesi infrapopliteal direkomendasikan kelas $\mathrm{Ila}^{4}$

Hasil setelah PTA arteri femoralpoplitea telah meningkat dari waktu ke waktu; tingkat patensi dari $87 \%$, 69\% dan $55 \%$ telah dilaporkan pada 1 , 3, dan 5 tahun. Sebuah penelitian acak tunggal yang membandingkan efektivitas pembedahan dengan terapi latihan menunjukkan perbedaan hasil yang nonsignifikan, khususnya untuk menilai jarak tempuh maksimal dan keperluan untuk revaskularisasi. ${ }^{24}$

Hasil dari revaskularisasi lebih baik pada pasien dengan $\mathrm{ABI}$ yang tinggi paska prosedur, menunjukkan bahwa efektivitas prosedur revaskularisasi tungkai secara langsung berkaitan dengan tingkat perbaikan gejala. Data dari penelitian langsung membandingkan terapi latihan dan PTA. Analisis data gabungan dari tujuh studi yang membandingkan latihan dengan PTA pada pasien dengan klaudikasio menunjukkan bahwa PTA menghasilkan peningkatan yang lebih besar dalam indeks ankle-brachial tetapi dengan tidak ada perbedaan yang signifikan dalam kualitas hidup. ${ }^{23}$

Terdapat evolusi terbaru dalam terapi endovaskular, khususnya untuk penggunaan balon dan stent yang dilapisi obat. Selain itu terdapat beberapa pendekatan termasuk atherektomi, cryoplasty, dan teknik laser untuk lesi infrapopliteal, tetapi tidak lebih efektif saat dibandingkan dengan terapi konvensional. Selain itu jauh lebih mahal dibandingkan prosedur yang lama.

\section{- Pembedahan}

Sedikit bukti yang mendukung penggunaan intervensi bedah untuk klaudikasio intermiten. TASC merekomendasikan bahwa operasi adalah pengobatan pilihan untuk pasien dengan lesi difus yang luas atau penyakit bertingkat (TASC D). ${ }^{23}$

\section{- Lesi Aortoiliaka}

Bypass aorto-biiliak atau bifemoral biasanya direkomendasikan pada lesi aortoiliaka yang difus (gambar 5). Teknik ini bisa dilakukan dengan pendekatan retroperitoneal atau bypass unilateral. Teknik operasi lainnya bisa dengan bypass axillo bifemoral (gambar 5) atau thoracis bifemoral. Tingkat kepatenan 10 tahun bypass aortobifemoral ini berkisar antara $80 \%$ sampai $90 \%$.
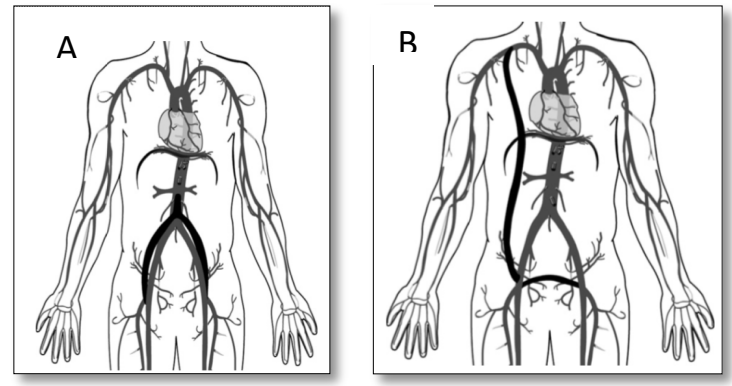

Gambar 5 Bypass Bilateral dari Aorta Abdominalis Infra Renal ke A. Femoralis B,Bypass Axillo Bifemoral ${ }^{1}$

\section{SIMPULAN}

Klaudikasio intermiten mempunyai faktor yang sama dengan proses atherosklerosis yaitu hipertensi, diabetes mellitus, merokok dan faktor keturunan. Sehingga terapi yang diperlukan adalah pengendalian faktor resiko, non invasif ataupun invasif. Sampai saat ini masih terdapat perdebatan efektifitas antara terapi invasif dan terapi non invasif. Diperlukan penelitian lebih lanjut untuk mengembangkan metode diagnosis dan keefektivitasan terapi.

\section{DAFTAR PUSTAKA}

1. Norgren L, Hiatt WR, Dormandy JA, Nehler MR, Harris KA, Fowkes FG, et al. TASC II inter-society consensus for the management of peripheral arterial disease. Eur J Vasc Endovasc Surg 2007; 33(1):S1-75

2. Fowkes FG, Rudan D, Rudan I, Aboyans V, Denenberg JO, McDermott MM, et al. Comparison of global estimates of prevalence and risk factors for peripheral artery disease in 2000 and 2010: A systematic review and analysis. Lancet. 2013; 382:1329-1340

3. Hirsch, A.T, Haskal ZJ, Hertzer NR, Bakal CW, Creager MA, Halperin JL, et al., ACC/AHA Guidelines for the Management of Patients with Peripheral Arterial Disease (lower extremity, renal, mesenteric, and abdominal aortic): a collaborative report from the American Associations for Vascular Surgery/Society for Vascular Surgery, Society for Cardiovascular Angiography and Interventions, Society for Vascular Medicine and 
Biology, Society of Interventional Radiology, and the ACC/AHA Task Force on Practice Guidelines (writing committee to develop guidelines for the management of patients with peripheral arterial disease)--summary of recommendations. J Vasc Interv Radiol, 2006; 17(9): p. 1383-97; quiz 1398.

4. Tendera M, Victor A, Marie LB, Iris B, Denis C, Jean PC, et al., ESC Guidelines on the diagnosis and treatmentof peripheral artery diseases. The Task Force on the Diagnosis and Treatment of Peripheral Artery Diseases of the European Society of Cardiology (ESC). Eur Heart J.2011; 32: 2851-2906.

5. Smith GD, Shipley MJ, Rose G. Intermittent claudication, heart disease risk factors, and mortality. The white hall study. Circ. 1990; 82:1925-1931

6. Kollerits B, Heinrich J, Pichler M, Rantner B, KleinWeigel P, Wolke G, et al. Intermittent claudication in the erfurt male cohort (erfort) study: Its determinants and the impact on mortality. A population-based prospective cohort study with 30 years of follow-up. Atherosclerosis. 2008; 198:214-222

7. Murabito JM, D'Agostino RB, Silbershatz $H$, Wilson WF. Intermittent claudication. A risk profile from the framingham heart study. Circ. 1997; 96:44-49

8. Gardner AW, Montgomery PS. The effect of metabolic syndrome components on exercise performance in patients with intermittent claudication. J Vasc Surg. 2008; 47:1251-1258

9. Van Kuijk JP, Flu WJ, Welten GM, Hoeks SE, Chonchol M, Vidakovic $R$, et al. Long-term prognosis of patients with peripheral arterial disease with or without polyvascular atherosclerotic disease. Eur Heart J. 2010; 31:992-999.

10. Igarashi $\mathrm{Y}$, Chikamori $\mathrm{T}$, Tomiyama $\mathrm{H}$, Usui $\mathrm{Y}$, Hida $S$, Tanaka $H$, et al. Clinical significance of inter-arm pressure difference and ankle-brachial pressure index in patients with suspected coronary artery disease. J Cardiol. 2007; 50:281289

11. Ouwendijk R, de Vries $M$, Stijnen $T$, Pattynama PM, van Sambeek MR, Buth J, et al. Multicenter randomized controlled trial of the costs and effects of noninvasive diagnostic imaging in patients with peripheral arterial disease: the DIPAD trial. AJR Am J Roentgenol 2008; 190:1349-1357.

12. Met R, Bipat S, Legemate DA, Reekers JA, Koelemay MJ. Diagnostic performance of computed tomography angiography in peripheral arterial disease: a systematic review and metaanalysis. Jama 2009; 301:415-424

13. Koelemay MJ, Lijmer JG, Stoker J, Legemate DA, Bossuyt PM. Magnetic resonance angiography for the evaluation of lower extremity arterial disease: a meta-analysis. Jama 2001; 285:1338-1345.

14. Momsen $A H$, Jensen MB, Norager CB, Madsen MR, Vestersgaard-Andersen T, Lindholt JS. Drug therapy for improving walking distance in intermittent claudication: a systematic review and meta-analysis of robust randomised controlled studies. Eur J Vasc Endovasc Surg 2009; 38: 463-474.

15. De Backer $T$, Vander Stichele R, Lehert $P$, Van Bortel L. Naftidrofuryl for intermittent claudication: meta-analysis based on individual patient data. BMJ 2009; 338:b603.

16. Hiatt WR, Regensteiner JG, Creager MA, Hirsch AT, Cooke JP, Olin JW, et al. Propionyl-L-carnitine improves exercise performance and functional status in patients with claudication. Am J Med 2001; 110:616-622

17. De Backer TL, Vander Stichele RH, Van Bortel LM. Bias in benefit-risk appraisal in older products: the case of buflomedil for intermittent claudication. Drug Saf 2009; 32:283-291

18. de Haro J, Acin F, Florez A, Bleda S, Fernandez $\mathrm{JL}$. A prospective randomized controlled study with intermittent mechanical compression of the calf in patients with claudication. J Vasc Surg 2010; 51:857-862.

19. Bendermacher BL, Willigendael EM, Teijink JA, Prins $\mathrm{MH}$. Supervised exercise therapy versus non-supervised exercise therapy for intermittent claudication. Cochrane Database Syst Rev 2006; 2:CD005263.

20. Murphy TP, Cutlip DE, Regensteiner JG, Mohler ER, Cohen DJ, Reynolds MR, et al. Supervised exercise versus primary stenting for claudication resulting from aortoiliac peripheral artery disease: six-month outcomes from the claudication: exercise versus endoluminal revascularization (CLEVER) study. Circ 2012; 125:130-139

21. Milani RV, Lavie CJ. The role of exercise training in peripheral arterial disease. Vasc Med 2007; 12:351-358.

22. White, Christopher. Intermittent Claudication. N Engl J Med 2007; 356:1241-50.

23. Greenhalgh RM, Belch JJ, Brown LC, Gaines PA, Gao L, Reise JA, et al. The adjuvant benefit of angioplasty in patients with mild to moderate intermittent claudication (MIMIC) managed by supervised exercise, smoking cessation advice and best medical therapy: results from two randomised trials for stenotic femoropopliteal and aortoiliac arterial disease. Eur J Vasc Endovasc Surg 2008; 36: 680-688. 